\title{
Inversion of Chlorophyll-a Concentration in Tropical Islands in China: a Case Study of Wuzhizhou Island
}

\author{
Feng-Xia WANG ${ }^{1,2, a,{ }^{*}}$ and Hui-Hui YAN ${ }^{3, b}$ \\ ${ }^{1}$ State Key Laboratory of Marine Resources Utilization in the South China Sea, Haikou, China \\ ${ }^{2}$ College of Tourism, Hainan University, Haikou, China; \\ ${ }^{3}$ Sihong Hongze Lake Ecotourism Resort Management Committee, Sihong, China; \\ asummer_wangfx@126.com, byanhh126@126.com \\ ${ }^{\star}$ Corresponding author
}

Keywords: Chlorophyll-a; inversion model; remote sensing; Wuzhizhou island waters

\begin{abstract}
Inversion of water components concentration of inland water body was hotspot and difficulty problem in water quality remote sensing. Based on the measured data of the concentrations of Chlorophyll-a in tropical islands waters area of China and the recent synchronous remote sensing image data, the inversion simulation was carried out to realize the spatio-temporal monitoring of the sea area. Through the analysis of the correlation between the radiation intensity of the water supply in the 1-4 bands of Wuzhizhou Island in 2010 and 2014 and the Chlorophyll-a concentration in Wuzhizhou Island, the Chlorophyll-a concentration inversion model was established. The distribution of Chlorophyll-a concentration in the study area was simulated, and the change of Chlorophyll-a concentration in four years was analyzed. The results showed that the Chlorophyll-a concentration in the blue and green bands was higher, and the ratio of the two as the independent variables could effectively reflect the Chlorophyll-a concentration in Wuzhizhou Island. The Chlorophyll-a concentration increased significantly from 2010 to 2014. Due to the impact of human activities, the concentration of Chlorophyll-a in tourism concentrated areas was low.
\end{abstract}

\section{Introduction}

Different sea areas are affected by many factors, and different compositions of matter in water have the different spectral curve. Water quality of large water area could be monitoring by using remote sensing technology by studying the spectral characteristics and establishing remote sensing inversion model of water quality. Among them, Chlorophyll-a concentration is an important index to measure the eutrophication degree of water. Collecting water samples in the field and doing experiments will take a large amount of physical, human and financial resources. At the same time, random point by point sampling cannot be carried out, and the coverage area is limited, while remote sensing has the advantages of fast, wide coverage, real-time dynamic monitoring. The research used remote sensing to carry out inversion simulation, which showed the advantages of low cost, time saving and energy saving. Meanwhile, it could study the whole regional situation extensively, improve the research accuracy and effectively monitor the status of the sea area.

With the rapid development of remote sensing technology, a lot of satellite images had been used in sea area monitoring, studies on the inversion of Chlorophyll-a concentration by remote sensing technology were increasing. Remote sensing inversion originated from the successful launch of Landsat-1, and was first developed in the 1970s by Klemas, who used MSS image data to estimate the suspended matter concentration and constructed a linear statistical model[1].Then the empirical regression model of Chlorophyll-a concentration was established using TM image and ocean measured data $[2,3,4,5]$. A lot of Chinese scholars established the inversion models based on remote sensing technology to simulate the concentration of Chlorophyll-a $[6,7,8,9]$. The research technology at home and foreign was becoming more and more mature, and the use of remote sensing inversion simulation method had attracted the attention of many scholars, becoming a new rapid monitoring, prediction mechanism. The inversion simulation methods were numerous, mainly 
divided into empirical, semi-empirical method, and analytical method. The band ratio method was more common, belonging to the empirical methods $[10,11,12]$.

\section{Study Area and Data Acquisition}

\section{Study Area}

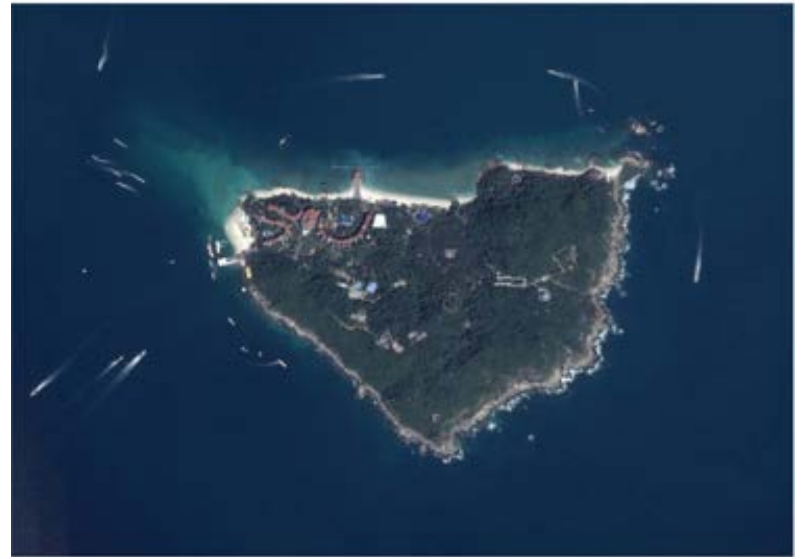

Fig. 1 The study area

Wuzhizhou Island $\left(109^{\circ} 45^{\prime} 42.60\right.$ "E $18^{\circ} 18^{\prime} 51.07$ "N) is located within Haitang Bay in tropical Hanan province, belonging to Sanya city and was called "Lovers Island". It has unique tropical island scenery and is named national 5A level scenic spot. The largest distance between north and south is 1100 meters, with a radius of 1.48 square kilometers (see Fig. 1). According to the development of the situation Wuzhizhou Island waters, the study area was 1000 meters above sea level domain Wuzhizhou Island inshore, mainly for the development of marine tourism. Wuzhizhou Island coastal waters have bathing beach, diving area, entertainment area at sea, marine ranching areas and other marine tourism area.

\section{Remote Sensing Data}

The remote sensing images required for the comparison of suspended solids concentration in the sea area of Wuzhihzou Island were derived from TM images of Landsat-5 satellite on June 12,2010 and WFV2 images of GF-1 satellite on June 3,2014. The two kinds of data were both the multi-spectral images, with same WGS_84_UTM Spatial Reference System. The former spatial resolution was $30 \mathrm{~m}$, containing seven bands, while the latter spatial resolution was $16 \mathrm{~m}$ with four bands. The inversion was mainly applied in blue, green, red and near-infrared four bands, the spectrum range of the two is not very different and can be used for the study of inversion contrast.

\section{Investigation Data}

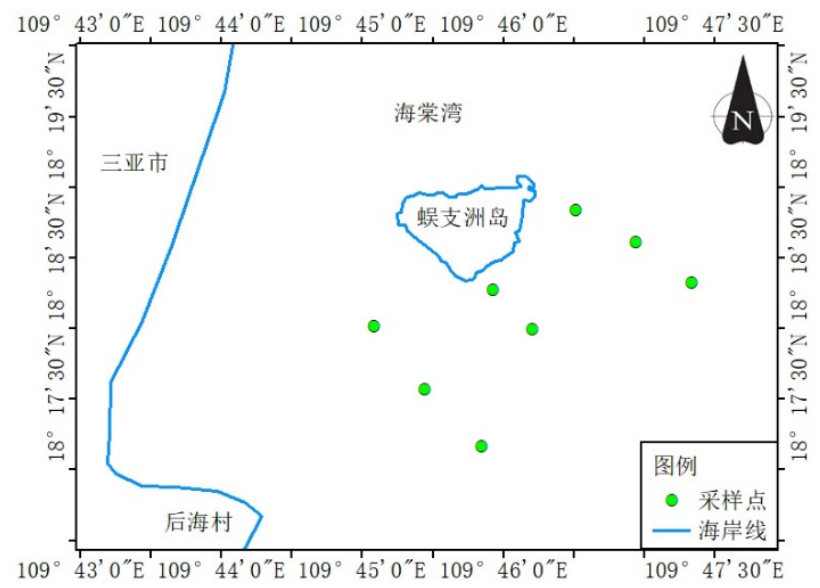

Fig. 2 Location distribution of field data acquisition 
The date of field sampling data of Wuzhizhou Island were June 11, 2010 and June 2, 2014. Investigations were made in 8 Survey stations (see Fig.2). The samples were collected in accordance with the "specification for oceanographic survey" and "marine monitoring" in, storage, transport and analysis, and according to weighing method to obtain concentration of suspended solids.

\section{Remote Sensing Data Processing}

The processing steps of remote sensing image data mainly included orthophoto correction, radiation correction, geometric correction and image clipping. Orthophoto correction was mainly to correct the deformation caused by the terrain, radiation correction was to eliminate the error of atmospheric absorption and scattering, geometric correction eliminated position, shape deformation, and cutting of the required research areas. Respectively, the function of RPC Orthorectification Using Reference Image in ENVI 5.3 was used for orthorectify, Radiometric Calibration for radiometric correction, FLAASH Atmospheric Correction for atmospheric correction, Select GCPs: Image to Image for geometric correction, and Subset Data from ROIs for image clipping.

\section{Inversion of Chlorophyll-a Concentration in Wuzhizhou Island}

Chlorophyll has absorption peaks in the blue and red outer bands, and reflection peaks in the green and near infrared bands. The inversion bands are selected according to the spectral characteristics of Chlorophyll-a in water. Through the analysis of the relationship between the concentration of Chlorophyll-a in the measured station and the radiance intensity of the image from wand ter, it was found that the correlation between Chlorophyll-a and band-1 was the strongest in 2010; however, the correlation between Chlorophyll-a concentration and the band-2 was strong in 2014. By analyzing the correlation between the Chlorophyll-a concentration of each band, it was convenient to select the proper bands to combined, and to build the inversion model.

\section{Chlorophyll-a Concentration Inversion Models}

With Landsat-5 TM 1-4 bands and combinations, the method of regression analysis was adopted to build the Chlorophyll-a concentration inversion model. The common regression function models included linear, exponential, logarithmic, exponential and polynomial. According to the correlation between the concentration of Chlorophyll-a and the radiation from the water brightness of different bands, proper bands were selected to do combination, to calculate the correlation between various band combination and Chlorophyll-a concentration significance analysis and goodness of fit(Table 1). It could be seen that the inversion model of polynomials was good, and the ratio combination of blue and green bands had the highest correlation with the significance level of P less than 0.05 and $\mathrm{R}^{2}$ value equaling to 0.942 , which indicated the best fitting effect. The Chlorophyll-a concentration inversion model of landsat-5 TM images on June 11, 2010 is:

$$
Y_{L-C h l-a}=1.311 X_{L}^{2}-2.348 X_{L}+1.171
$$

In the formula, $X_{L}=$ Band1/Band2 referred to the ratio of radiation luminance values in the first and second bands of landsat-5 TM image bands; $Y_{L-C h l-a}$ referred to the concentration of chlorophyll a in the 2010 landsat-5 TM image inversion simulation, unit: $\mathrm{mg} / \mathrm{m}^{3}$.

Table 1 Landsat TM estimation model for chlorophyll a concentration in 2010

\begin{tabular}{ccccc}
\hline $\begin{array}{c}\text { The dependent } \\
\text { variable }\end{array}$ & Arguments & $\mathrm{R}^{2}$ & P value & model \\
\hline $\mathrm{Y}_{\mathrm{L}-\text { Chl-a }}$ & $\mathrm{X}_{\mathrm{L}}=\mathrm{B} 1 / \mathrm{B} 2$ & 0.942 & $0.041 *$ & $\mathrm{Y}_{\mathrm{L}-\text { Chl-a }}=1.311 \mathrm{X}_{\mathrm{L}}{ }^{2}-2.348 \mathrm{X}_{\mathrm{L}}+1.171$ \\
$\mathrm{Y}_{\mathrm{L}-\text { Chl-a }}$ & $\mathrm{X}_{\mathrm{L}}=\mathrm{B} 2 / \mathrm{B} 1$ & 0.933 & 0.093 & $\mathrm{Y}_{\mathrm{L}-\text { Chl-a }}=1.148 \mathrm{X}_{\mathrm{L}}{ }^{2}-2.605 \mathrm{X}_{\mathrm{L}}+1.592$ \\
$\mathrm{Y}_{\mathrm{L}-\text { Chl-a }}$ & $\mathrm{X}_{\mathrm{L}}=(\mathrm{B} 2-\mathrm{B} 1) /(\mathrm{B} 2+$ & 0.937 & 0.067 & $\mathrm{Y}_{\mathrm{L}-\text { Chl-a }}=4.952 \mathrm{X}_{\mathrm{L}}{ }^{2}-0.583 \mathrm{X}_{\mathrm{L}}+0.134$ \\
& $\mathrm{~B} 1)$ & & & \\
$\mathrm{Y}_{\mathrm{L}-\text { Chl-a }}$ & $\mathrm{X}_{\mathrm{L}}=\mathrm{B} 1 / \mathrm{B} 4$ & 0.919 & 0.327 & $\mathrm{Y}_{\mathrm{L}-\text { Chl-a }}=0.014 \mathrm{X}_{\mathrm{L}}{ }^{2}-0.093 \mathrm{X}_{\mathrm{L}}-0.280$ \\
\hline
\end{tabular}

Note: *Correlation 0.05 significant level 
According to the correlation between each band and Chlorophyll-a of GF-1 WFV2 on June 3, 2014, the strongly correlated bands were selected for combined calculation. It was found that the blue and green combination band had significant correlation with Chlorophyll-a concentration with the significant level of $\mathrm{P}$ value less than 0.01 , of which the band-2/band- 1 ratio was the highest goodness-of-fit of $\mathrm{R}^{2}=0.843$ (table 2). So the Chlorophyll-a concentration of 2 June 2014 inversion model was as follows:

$$
\mathrm{Y}_{\mathrm{G}-\mathrm{Chl}-\mathrm{a}}=13.844 \mathrm{X}_{\mathrm{G}}^{2}-31.371 \mathrm{X}_{\mathrm{G}}+17.915
$$

In the formula, $X_{G}=B$ and2/Band1 referred to the ratio of the radiation luminance value of the second and first band of GF-1 WFV2 image in 2014; $Y_{G \text {-Chl-a }}$ referred to the concentration of chlorophyll a simulated by GF-1 WFV2 image inversion, unit: $\mathrm{mg} / \mathrm{m}^{3}$.

Table 2 GF-1 WFV2 estimation model for Chlorophyll-a concentration in 2014

\begin{tabular}{|c|c|c|c|c|}
\hline $\begin{array}{c}\text { The dependent } \\
\text { variable }\end{array}$ & Arguments & $\mathrm{R}^{2}$ & P value & model \\
\hline $\mathrm{Y}_{\mathrm{G}-\mathrm{Chl}-\mathrm{a}}$ & $\mathrm{X}_{\mathrm{G}}=\mathrm{B} 2 / \mathrm{B} 1$ & 0.843 & $\begin{array}{c}0.005 \\
* *\end{array}$ & $\begin{array}{c}\mathrm{Y}_{\mathrm{G}-\mathrm{Chl}-\mathrm{a}}=13.844 \mathrm{X}_{\mathrm{G}} 2-31.371 \mathrm{X}_{\mathrm{G}}+ \\
17.915\end{array}$ \\
\hline $\mathrm{Y}_{\mathrm{G}-\mathrm{Chl}-\mathrm{a}}$ & $\mathrm{X}_{\mathrm{G}}=\mathrm{B} 1 / \mathrm{B} 2$ & 0.830 & $\begin{array}{c}0.003 \\
* *\end{array}$ & $\begin{array}{c}\mathrm{Y}_{\mathrm{G}-\mathrm{Chl}-\mathrm{a}}=12.713 \mathrm{X}_{\mathrm{G}} 2-22.133 \mathrm{X}_{\mathrm{G}}+ \\
9.8127\end{array}$ \\
\hline$Y_{G-C h l-a}$ & $\begin{array}{c}\mathrm{X}_{\mathrm{G}}=(\mathrm{B} 2-\mathrm{B} 1) /(\mathrm{B} 2+ \\
\mathrm{B} 1)\end{array}$ & 0.836 & $\begin{array}{c}0.004 \\
* *\end{array}$ & $\mathrm{Y}_{\mathrm{G}-\mathrm{Chl}-\mathrm{a}}=54.10 \mathrm{X}_{\mathrm{G}} 2-6.988 \mathrm{XG}+0.389$ \\
\hline
\end{tabular}

Note: $* *$ Correlation significance 0.01 level

\section{Chlorophyll-a Concentration Distribution}
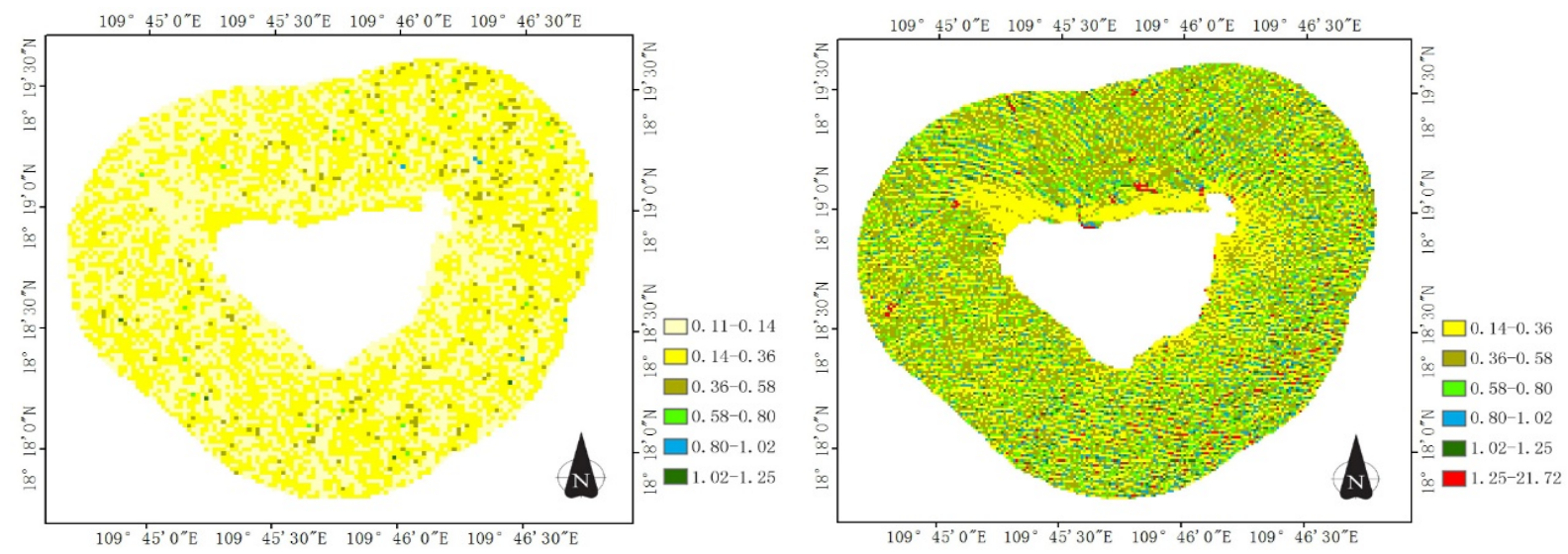

Fig. 3 Distribution of chlorophyll-a concentration (unit: $\mathrm{mg} / \mathrm{m}^{3}$ )

According to the established Chlorophyll-a concentration inversion model, using band editing tools in ENVI 5.3, the chlorophyll concentration distribution in Wuzhizhou island waters in June 2010 and in June 2014 were obtained. The results were shown in Fig. 3. On June 11, 2010, Chlorophyll-a concentration of Wuzhizhou island waters was relatively low, within the range of $0.11-1.25 \mathrm{mg} / \mathrm{m}^{3}$.According to Chlorophyll-a attribute table by ArcGIS10.3, it was found that $97 \%$ of the area of chlorophyll concentration was lower than $0.36 \mathrm{mg} / \mathrm{m}^{3}$, meanwhile Chlorophyll-a concentration of bathing beach, motor boats, cruise ship tourism area in the north and northwest of Wuzhizhou island was low, the chlorophyll in the northeast area was higher with the decreasion from east to west. On June 2, 2014, Chlorophyll-a concentration of Wuzhizhou island ocean rised obviously, within the scope of the concentration from 0.14 to $21.72 \mathrm{mg} / \mathrm{m}^{3} .96 \%$ of the area of chlorophyll concentration in the range of $0.14-1.02 \mathrm{mg} / \mathrm{m}^{3}$, and the Chlorophyll-a concentration in the southeast area was higher, while the concentration of bathing beach in north and northwest area was low. In total, the chlorophyll concentration of Wuzhizhou island was low, which mean high water quality and high transparency. 


\section{Chlorophyll-a Concentration Evolution}

In Fig.3, the grade classification and color blocks of Chlorophyll-a concentration distribution in 2010 and 2014 was consistent. It was obvious that the concentration of Chlorophyll-a increased in 2014 from the color changes.

(1) Base changes. In 2010, the minimum concentration of Chlorophyll-a was $0.11 \mathrm{mg} / \mathrm{m}^{3}$ and the maximum was $1.25 \mathrm{mg} / \mathrm{m}^{3}$; While in 2014, the minimum concentration of Chlorophyll-a was 0.14 $\mathrm{mg} / \mathrm{m}^{3}$, the maximum value is $21.72 \mathrm{mg} / \mathrm{m}^{3}$.

(2) Scope change. $45 \%$ of the study area of Chlorophyll-a concentration was less than 0.14 $\mathrm{mg} / \mathrm{m}^{3}$ in 2010, while that in 2014 was zero. 2\% of the study area of Chlorophyll-a concentration was greater than $1.25 \mathrm{mg} / \mathrm{m}^{3}$, while that in 2010 was zero. The range of Chlorophyll-a concentrations in 2010 was 1.14, compared with 21.58 in 2014.

(3) Concentration changes. In 2010, 97\% of the study area of the Chlorophyll-a concentration was lower than $0.36 \mathrm{mg} / \mathrm{m}^{3}$, while in 2014 , the percent was $64 \%$. After four years' development, the concentration range was significantly increased.

(4) Distribution changes. In 2010, the high concentration of Chlorophyll-a was mainly located in the northeast of the study area, showing a general trend of decreasing concentration from east to west. In 2014, Chlorophyll-a concentration was high in the southeast of the study area, where was the marine ranching area, with the effect of breeding and agglomeration of marine life, promoting the growth of phytoplankton. However, the concentration of Chlorophyll-a in the northern and northwestern regions was low, where was the concentration area of tourism activities and was greatly affected by human factors.

\section{Conclusion}

(1) By the correlation analysis between band combinations and the Chlorophyll-a concentration of Wuzhizhou island waters, it was found that the correlation between the first and second band was higher, which could be used to estimate chlorophyll concentration of the Wuzhizhou island ocean more accurately. Among them, the polynomial inversion model with the first and second bands ratio as independent variables was the best.

(2) Chlorophyll-a concentration of Wuzhizhou island sea area increased significantly from 2010 to 2014. The Chlorophyll-a concentration in the northern and northwestern tourist areas was significantly lower than that in other areas, which was mainly affected by recreational activities such as sea bathing, diving and water sports.

(3) The inversion model of Chlorophyll-a concentration in the Wuzhizhou Island surrounding waters had important reference value and obvious regional characteristics for Wuzhizhou Island is a model of China's tropical island tourism. At the same time, the concentration of Chlorophyll-a and combination bands revealed a significant correlation, fitting degree is more than $94 \%$, which was very rare in other studies, and had important guidance and practical value to study China's tropical island Marine monitoring and tourism development.

\section{Acknowledgement}

The research is funded by Hainan Natural Science Foundation of China: Study on the Coupling Mechanisms between Tourism Development and Ecological Environment in Tropical Marine Ranch -take Wuzhizhou Island as an example(417068); Hainan Provincial Department of Education Project: Monitoring and Evaluation of Remote Sensing South China Sea Ranch environmental impact (Hnky2016ZD-6);

\section{References}

[1] Klemas V, Bartlett D, Philpot W, et al. Coastal and Estuarine Studies with ERTs-1 and Skylab [J]. Remote Sensing Env, 1974, 3(03): 153-174. 
[2] Sathyendnoth S, Prieu RL, Morel A. A Three-component Model of Ocean Color and its Application to Remote Sensing of Phytoplankton Pigments in Coastal Waters [J]. International Journal of Remote Sensing, 1989, 10 (08): 1373-1394.

[3] Ekstrand. Landsat TM Based Quantification of Chlorophyll-a during Algae Blooms in Coastal Waters [J]. International Journal of Remote Sensing, 1992,13 (10): 1913-1926.

[4] Brivio P A, Giardino C, Zilioli E. Determination of Chlorophyll Concentration Changes in Lake Garda Using an Image-based Radiative Transfer Code for Landsat TM Images [J] International Journal of Remote Sensing, 2001, 22 (2-3): 487-502 .

[5] Loisel H, Vantrepotte V, Ouillon S, et al. Assessment and Analysis of the Chlorophyll-a Concentration Variability over the Vietnamese Coastal Waters from the MERIS Ccean Color Sensor (2002-2012) [J]. Remote Sensing of Environment, 2017, 190: 217-232.

[6] HUANG Changchun, LI Yunmei, WANG Qiao, LU Heng, SUN Deyong. Generalized Bio-optical Inversion Model of Suspended Particulate Matter and Chlorophyll[J]. Journal of Infrared and Millimeter Waves, 2013, (05): 462-467.

[7] MA Wandong, WANG Qiao, WU Chuanqing, et al. Water Chlorophyll Reflectance Remote Sensing Inverse Modeling Based on Peak Area[J]. Geo-Information Science,2014,16 (06): 965-970.

[8] ZHANG Yibo, ZHANG YunLin, ZHA Yong, et al. the Estimated Total Suspended Substance Concentration of Xin'anjiang Reservoir Based on Landsat 8 images[J]. Environmental Sciences, 2015,36 (01): 56-63. Z.

[9] WANG Jingqi. Chlorophyll Inversion and Spectral Morphology Classification of Lake Water Based on GF-1 Images[D]. East China Institute of Technology,2016.

[10]XIONG Zhu, DING Shimin, XIAO Hongyan, et al. Research Progress in Algorithms of Chlorophyll-a Concentration in Water Remote Sensing Inversion [J] western China Science and Technology, 2015,14 (10): 16-20.

[11]ZENG Qun, ZHANG Haidong, CHEN Xiaoling, et al. Remote Sensing Atmospheric Correction Algorithm Evaluation MERIS Image in Water Environmental- a Case Study of Chlorophyll-a Concentration Inversion in Boyanghu Lake [J] Lake Sciences, 2016,28 (06): 1306-1315.

[12]YANG Xianping. Remote Sensing Estimation of Surface Suspended Sediment and Diffuse Attenuation Coefficient in the Changjiang Estuary and Adjacent Sea Area[D]. East China Normal University, 2016. 